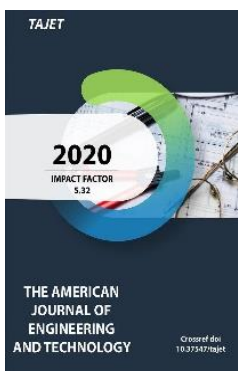

Copyright: Original content from this work may be used under the terms of the creative commons attributes 4.0 licence.

\section{Analogical Model Development Methodology For Mathematical Modeling Of Energy Efficiency Control System}

\author{
Mirzoyev Narzullo Nuridddinovich \\ The Senior Teacher Of Department Of Energy Audit, Bukhara Engineering Technological \\ Institute, Bukhara, Uzbekistan
}

\title{
ABSTRACT
}

This article presents the methods and principles of developing an analogue model for mathematical modeling of energy efficiency management systems.

\section{KEYWORDS}

Energy efficiency, automatic control, analog models, heat and energy sources, device, apparatus, technological line, communications, spinning-preparation, weaving-preparation, weaving, assistant, boiler room.

\section{INTRODUCTION}

To develop an analog model of the energy efficiency control system for grain processing industry, we use the methods and principles of the theory of automatic control. In practice, an analog model is understood as an organizational and structural diagram of a control system. The mathematical model of the system is created quickly and reliably when the accuracy and transparency of analog models is high [1].

The control system is created as a combination of two systems: control and controlled (control object). The control subsystem generates control actions $\mathrm{G}(\mathrm{t})$, the controlled subsystem (control object) is under the influence of control actions. 
The influence of the control subsystem on the control object is considered as a process, and the influence of control is considered as a sequential change in the values of $\mathrm{G}(\mathrm{t})[1]$.

The relational model of the formation of the control effect is presented in Table 1.1.

The initial impact $\mathrm{q}(\mathrm{t})$ is formed on the basis of the normalization of energy costs, the initial data for which are individual objects (device, apparatus, technological line, communications), manufactory (mill, elevator, feed mill, boilerroom), in general, make up the energy balance of the enterprise.

\section{MATERIALS AND METHODS}

Consumption rates of heat and energy sources are developed in natural units adopted during planning per unit of finished products (tons of products, etc.) or per unit of work (compressor, refrigerator, etc.).

Table 1.1.

\section{Relational model of control action formation}

\begin{tabular}{|c|c|c|}
\hline evel & The essence of the degree & Result \\
\hline & $\begin{array}{l}\text { 1. Collection of information, transfer to points of } \\
\text { collection and processing } \\
\text { 2. Analysis of incoming, collected and unaware } \\
\text { information on energy saving. } \\
\text { 3. External factors: the energy saving system and its } \\
\text { changing trends, tariffs, regulatory framework for } \\
\text { energy consumption and energy saving, the state of } \\
\text { the environment. }\end{array}$ & $\begin{array}{l}\text { Making a decision on the } \\
\text { development of strategic } \\
\text { and short-term plans for } \\
\text { increasing energy efficiency } \\
\text { of production }\end{array}$ \\
\hline I & $\begin{array}{l}\text { 1. Conduct energy audits at all stages of energy } \\
\text { consumption and change } \\
\text { 2. Creation of energy balances of energy consumption }\end{array}$ & $\begin{array}{l}\text { Determination of the } \\
\text { energy intensity of the } \\
\text { product, the potential for } \\
\text { energy saving both for the } \\
\text { enterprise as a whole and } \\
\text { for individual processes and } \\
\text { equipment. }\end{array}$ \\
\hline II & $\begin{array}{l}\text { 1. Prioritize energy conservation } \\
\text { 2. Feasibility study of energy saving measures. } \\
\text { 3. Financial analysis of energy saving projects. }\end{array}$ & $\begin{array}{l}\text { Development of an energy } \\
\text { saving program }\end{array}$ \\
\hline
\end{tabular}


The American Journal of Engineering and Technology

(ISSN - 2689-0984)

Published: October 31, 2020 | Pages: 55-61

Doi: https://doi.org/10.37547/tajet/Volumeo2Issue10-10

\begin{tabular}{|c|c|c|}
\hline $\mathrm{V}$ & 1. Standardization of energy consumption & $\begin{array}{l}\text { 1. Formation of the } \\
\text { beginner setting action } \\
q(t)\end{array}$ \\
\hline & $\begin{array}{l}\text { 1. Comparison of the initial (setting) action } \mathrm{q}(\mathrm{t}) \text { and } \\
\text { the controlled parameter } \mathrm{y}(\mathrm{t}) \\
\text { 2. Analysis of deviations } \mathrm{S}=[\mathrm{q}(\mathrm{t}) \sim \mathrm{y}(\mathrm{t})]\end{array}$ & $\begin{array}{l}\text { Formation of controlled } \\
\text { action } G(t)\end{array}$ \\
\hline
\end{tabular}

Deviation of the controlled parameter from the norm is an integral part of the development and improvement of the functional system. The very deviation from the norm is an incentive to return to normal. The source of deviation is the environment, external influences.

External influences $f(t)$ (change in quantity, quality, energy parameters, implementation of energy-saving projects, implementation of energy-saving measures, such as frequency-controlled transmission of electricity, thermal insulation, use of thermal energy, etc.) varies depending on known and random laws [2].

During the implementation of technological processes associated with energy changes are accompanied by a large number of factors affecting their course and often of a random nature.

At any given time, it is impossible to define the process by taking into account all factors in advance. In accordance with the problems that need to be solved in the process, it is possible to take into account the circumstances that arise in order to influence the process only through operational participation in the process every time trends or deviations arise in the process.

Functional systems arise due to the qualitative ordering of relationships under the influence of the external environment: informational resonance, as a signal of deviation (in the form of negative feedback), began to form closed circuits of self-regulation homeostasis.
In the energy efficiency management system, the feedback (value of the monitored parameter) is formed as the lowest level of the control output and the highest level of the input.

Controllable parameter y $(t)$ - energy efficiency indicator - coefficient of efficiency of standard energy consumption at the consumer:

$$
\eta=\varepsilon_{n} / \varepsilon
$$

where $\mathrm{S}$ is the generalized direct energy consumption;

$$
\varepsilon=R_{E} E+R_{W} W+R_{B} B_{n p}
$$

Here:

E - power consumption;

W - heat energy consumption;

Bnp - direct use fuel consumption;

$\mathrm{RE}, \mathrm{RW}, \mathrm{RB}$ - conventional fuel equivalents.

$S_{P}$ is the generalized final energy consumption (useful work), which is determined in a normative manner on the basis of electricity, heat energy, direct use fuel power Vs and heat $v t$ measured in the devices.

$$
\begin{aligned}
\varepsilon_{n} & =R_{E} E \eta_{E}+R_{W} W \eta_{W}+R_{B}^{T} B_{C} \eta_{C}+ \\
R_{B} B_{T} \eta_{T} & (1.3)
\end{aligned}
$$

where $\eta \mathrm{E}, \eta \mathrm{W}, \eta \mathrm{C}, \eta^{\mathrm{T}}$ are respectively weighted average coefficients of efficient use of energy sources in the processes of electricity consumption, heat energy, direct fuel consumption in capacities Vs and heat $\mathrm{W}$ devices. 
The American Journal of Engineering and Technology

(ISSN - 2689-0984)

Published: October 31, 2020 | Pages: 55-61

Doi: https://doi.org/10.37547/tajet/Volumeo2Issue10-10

In theory, $\mathrm{R}^{\top}{ }_{\mathrm{B}}$ is the energy equivalent of fuel equivalent [3].

The control system provides for an additional control effect $G_{d}(t)$, which is aimed at increasing the level of training of employees and workers on energy saving issues, providing engineers and workers with information on ways and means of improving energy efficiency.

Additional management impact also includes two groups of information documents that make up the organizational and methodological support of the management system.

\section{RESULT AND DISCUSSION}

By organizational support we mean a set of organizational and managerial documents that determine the procedure for performing the management function, who, what and when. These include organizational standards, unit regulations, job descriptions, decisions and orders.

A methodology is a set of guidelines that define how a specific function is performed.

An analog model of the developed control system is shown in Figure 1.1.

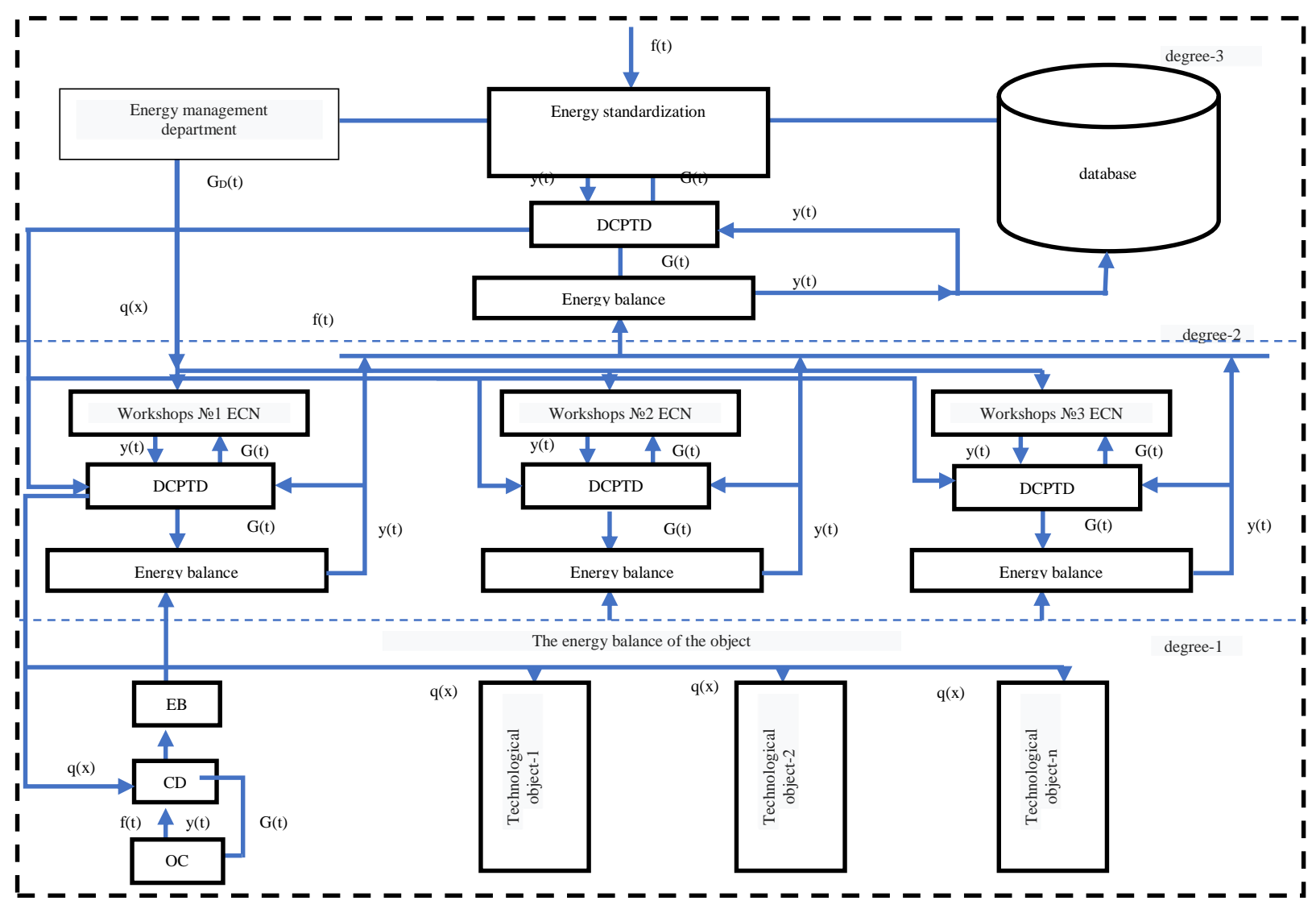

Figure 1.1. Analog model of the control system

The following symbols are adopted in the scheme: DCPTD- a device for collecting, processing and transmitting data; ECN - energy consumption normalization; EB - energy balance; $C D$ - control device; $O C$ - object of control. 
The database in this system consists of specially organized (structured) data and an integrated set of relationships between them. In other words, it is a clear image of the subject area of information.

Database design begins with an analysis of the domain and potential customer requirements.

The subject of this management system is the energy efficiency of the textile industry.
Consumers are energy management employees. The consumer requirements set out in the information support are considered in the first section of the work.

The database design process can be divided into a number of interrelated stages, each of which has its own characteristics and methods.

Figure 1.2 shows the typical design steps for a database.

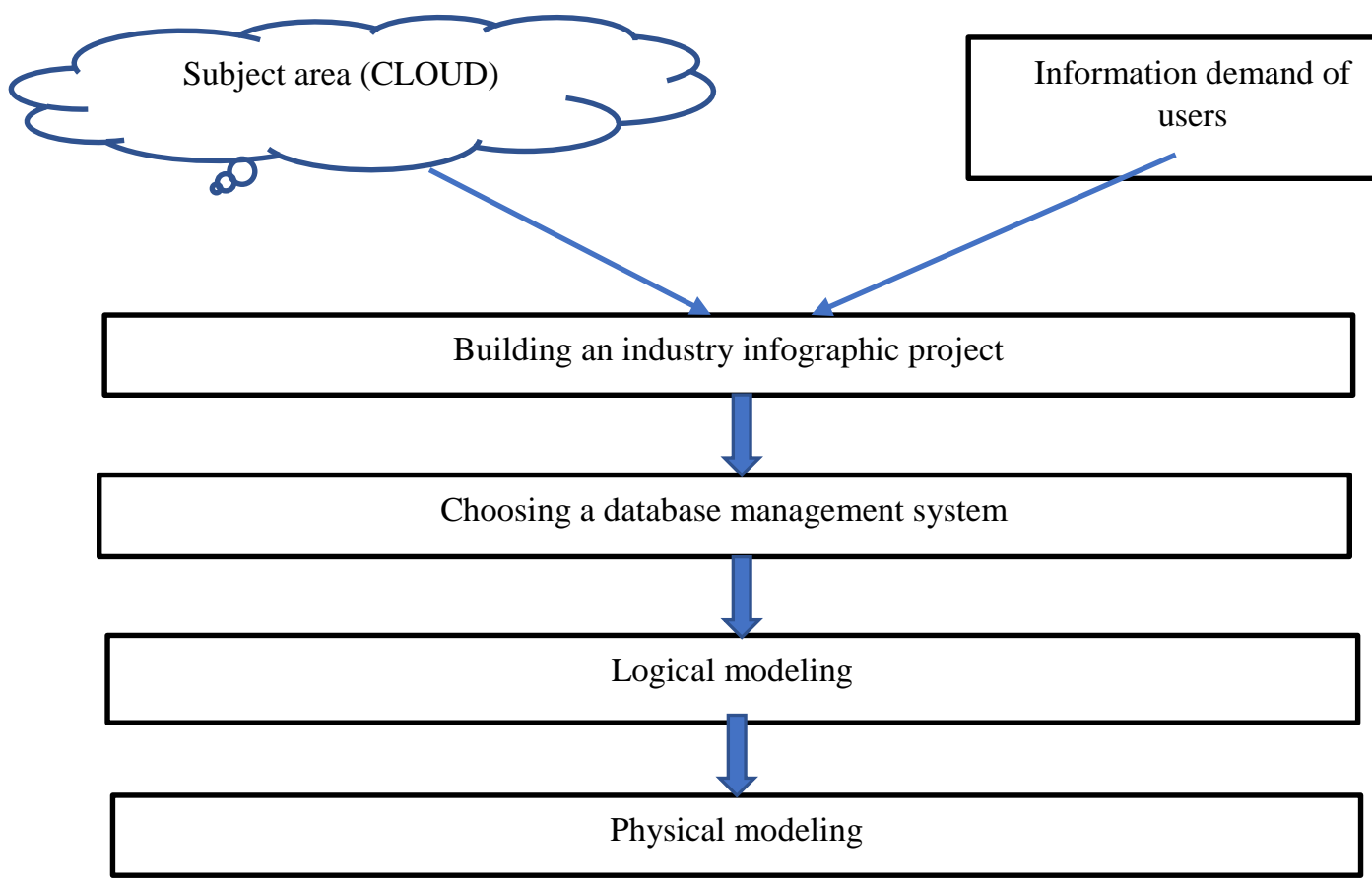

Figure 1.2. Database design stages

An infological (information-logical) model is a descriptive (informal) model of the subject area, which semantically defines the information (entity) and relationships between them that are of interest to users of the database from the subject area.

At the logical design stage of the database, the information divided in the infographic model is displayed as data in formats using the selected MBBT (Database Management System). The conceptual model describes data and connections stored on a computer, that is, a specific MBBT is directly related to the data description language. The challenge for physical design is to choose a method for storing data on physical media and methods of accessing it using the capabilities provided by MBBT. 
Figure 1.3 shows the infographic model "The third level of the energy efficiency management system".

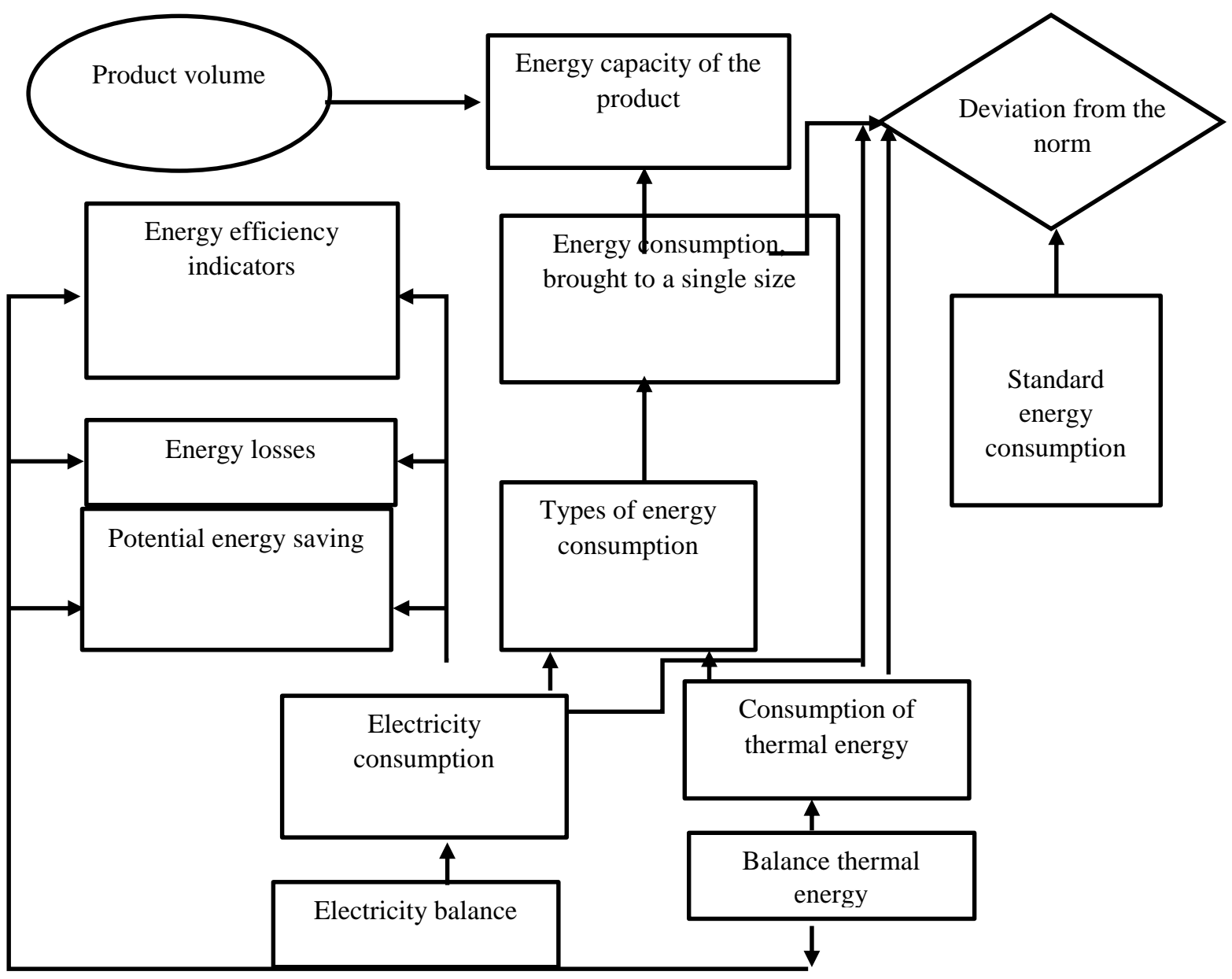

Figure 1.3. Infological model "The third level of the energy efficiency management system"

In conclusion, we can say that the infographic models of the first and second levels of the energy efficiency management system have the same features as the third level.

\section{REFERENCES}

1. Cheremisin V.T., Nikiforov M.M. The system of monitoring and operational management of the consumption of fuel and energy resources // Railway transport. 2010. No.11. S. 64-65.

2. Cheremisin V.T., Zazhirko V.N., Nikiforov M.M. [and others]. Development of a subsystem for analyzing and systematizing the components of electricity consumption for operational needs in a general monitoring system for electricity consumption and losses // Research of the processes of interaction of railway transport objects with the environment: Sat. scientific. Art. / OmGUPS. Omsk, 2003.S. 174-186. 
The American Journal of Engineering and Technology (ISSN - 2689-0984)

Published: October 31, 2020 | Pages: 55-61

3. Siddikov I.Kh., Abdumalikov A.A., Mirzoev N.N., Amurova N.Yu., Maksudov M.T., Khonturaev I.M. Software for the study of reliability indicators and the operating state of control elements and energy efficiency management. Registered computer software Agency for Intellectual Property of the Republic of Uzbekistan. DGU 08003.27.03.2020 N2020 0325. 